\title{
The perception of school food-service professionals on the implementation of the Healthy, Hunger-Free Kids Act of 2010: a mixed-methods study
}

\author{
Zainab Rida ${ }^{1, *}$, Elisha Hall², Saima Hasnin ${ }^{3}$, Jessie Coffey ${ }^{1}$ and Dipti A Dev ${ }^{3}$ \\ ${ }^{1}$ Nebraska Department of Education, 301 Centennial Mall South, Lincoln, NE 68509-4987, USA: ${ }^{2}$ No affiliation \\ specified, Atlanta, GA, USA: ${ }^{3}$ Department of Child, Youth and Family Studies, University of Nebraska-Lincoln, \\ Lincoln, NE, USA
}

Submitted 26 January 2018: Final revision received 4 March 2019: Accepted 8 March 2019: First published online 23 April 2019

\begin{abstract}
Objective: To: (i) understand the nutrition attitudes, self-efficacy, knowledge and practices of school food-service personnel (SFP) in Nebraska and (ii) identify potential barriers that schools face in offering healthy school meals that meet the US Department of Agriculture (USDA) nutrition standards.

Design: Convergent parallel mixed-methods study.

Setting: Kindergarten-12th grade schools in Nebraska, USA.

Participants: SFP (260 survey participants; fifteen focus group participants) working at schools that participate in the USDA National School Lunch Program. Results: Mixed-methods themes identified include: (i) 'Mixed attitudes towards healthy meals', which captured a variety of conflicting positive and negative attitudes depending on the situation; (ii) 'Positive practices to promote healthy meals', which captured offering, serving and promotion practices; (iii) 'Mixed nutrition-related knowledge', which captured the variations in knowledge depending on the nutrition concept; and (iv) 'Complex barriers', which captured challenges with time, support and communication.

Conclusions: The study produced relevant findings to address the barriers identified by SFP. Implementing multicomponent interventions and providing training to SFP may help reduce some of the identified barriers of SFP.
\end{abstract}

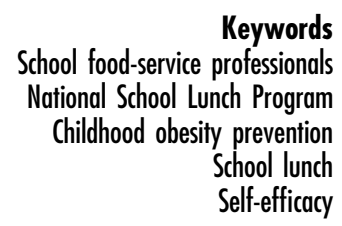

The school environment plays a critical role in promoting children's healthy food choices, preventing childhood obesity, and combating problems associated with poor nutrition and physical inactivity ${ }^{(1-6)}$. School-aged children consume up to three meals and a snack at school on school days, indicating that school meal practices and school wellness policies have the potential to influence child and youth dietary behaviour, making schools an ideal setting for promoting healthy eating to children and their families ${ }^{(4-8)}$. According to the US Department of Agriculture (USDA) Food and Nutrition Service, $95 \%$ of children attend public or private schools and $66 \%$ of these students participate in the National School Lunch Program (NSLP) ${ }^{(9-14)}$. The Food Research \& Action Center reported that participation in the NSLP in 2015-2016 reached approximately 21.6 million children daily in schools ${ }^{(13)}$. Approximately $35 \%$ of students' daily energy intake is attributed to eating school lunch and $47 \%$ when eating both school breakfast and school lunch ${ }^{(15)}$. This a significant area where policy and stakeholders can have influence on the foods and beverages consumed in schools $^{(11,15)}$.

The USDA has recognized that school environments play an integral role in the development of a child's eating habits, as approximately 60 million children are exposed to food in these settings ${ }^{(9-12)}$. With the introduction of the Healthy, Hunger-Free Kids Act of 2010 (HHFKA) $^{(9-12)}$, nutrition standards now require the NSLP and the School Breakfast Program to include more fruits, vegetables and whole grains, while limiting unhealthy foods and beverages such as those high in sugar and fat ${ }^{(10-12)}$. Additionally, the final rule, Local School Wellness Policy Implementation under HHFKA 2010, was released and required all schools that participate in the NSLP to establish a wellness policy with goals for nutrition education, physical activity and wellness, as well as other requirements for nutrition standards, inclusions of stakeholders and updates to the community.

School food-service professionals (SFP) have a varied and multifaced role in child nutrition programmes. For 
example, school food-service directors oversee the operation and administration of school meal programmes, whereas school food-service staff/employees are responsible for preparing, cooking and serving menu items. In some larger school districts, directors of school food services may have supervisory employees who provide support for menu planning, recipe development, financial administration and more. In rural and small districts, directors have numerous responsibilities and handle multiple facets of school meal programmes ${ }^{(13)}$. Regardless of their roles, SFP are responsible for preparing, offering and serving children meals that meet these standards. Foods that SFP serve to children are known to have an influence on their food consumption ${ }^{(14-18)}$. According to Eagen et al. cited in Wechsler et al., student participation is the number one concern of SFP; however, serving a menu of healthy foods that compete with available competitive foods (foods and beverages sold to students on school campus during the school day outside the reimbursable meal programmes) can be a major obstacle for the NSLP and $\mathrm{SFP}^{(19)}$. Limited preparation and serving space, in addition to insufficient meal periods, impact food-service options ${ }^{(20)}$. Depending on the area SFP work in, some may face more challenges than others. Research shows that more than $50 \%$ of public schools in the USA are in rural areas. These areas face many challenges at all district levels of operation, which constantly needs highly trained and qualified staff ${ }^{(21)}$. Cornish et al. identified many obstacles that affect school meal operations in rural districts including high transportation costs, poor Internet connections, limited technology training and additional equipment requirements ${ }^{(22)}$.

Despite barriers, facilitators such as educating SFP can also influence the ability to serve healthy foods. When school SFP were provided education on identification of whole grains, more whole grains were added to the menu, which suggests that increased knowledge influences school lunch $^{(23)}$. Additionally, self-efficacy is a significant contributor to behaviour, defined as an individual's belief in his/her ability to take action to produce desired outcomes $^{(24)}$. With SFP at the front line of serving healthy school meals ${ }^{(8,9)}$, and given the changes in school meal patterns as a result of the $\operatorname{HHFKA}^{(10,12)}$, there is a need to understand the role of SFP in serving healthy school meals in school settings. It is also important to understand the nutrition knowledge, attitudes and barriers of SFP to identify avenues of action in which changes can be made in the school nutrition programme, which is highly absent from the present literature.

Therefore, the purpose of the present study was to assess the nutrition attitudes, self-efficacy, practices and knowledge of SFP in Nebraska, to address the present literature gap related to SFP. A secondary purpose was to identify potential barriers that SFP face to offer healthy school meals that meet the USDA nutrition standards.

\section{Methods}

\section{Study design}

A mixed-methods approach was utilized in the present study to understand the nutrition knowledge, attitudes, practices, self-efficacy and barriers of SFP in Nebraska. A convergent parallel mixed-methods design was used, in which qualitative and quantitative data were collected in parallel, analysed separately and then merged ${ }^{(25)}$. Quantitative data were collected in the form of surveys from the school food-service directors/managers who are involved in service delivery for school meals in Nebraska. Qualitative data were collected through focus groups to explore the beliefs and current practices of SFP. The reason for utilizing both quantitative and qualitative methods was to get a comprehensive understanding of SFP's perspectives in serving healthier school meals. The qualitative findings provided the context for the interpretation of the quantitative data.

\section{Sample}

\section{Quantitative}

A convenience sample was selected for a paper survey targeting a wide range of SFP in Nebraska. Paper surveys were distributed at mandated trainings for audiences who work in school food-service settings. With release of the new school meal pattern, the Nebraska Department of Education developed a six-hour training for all SFP; these trainings were held in Lincoln, Omaha, Kearney, Norfolk, North Platte, Scottsbluff and Grand Island. Four hundred and eleven participants attended these trainings and 260 participants responded to the paper survey.

\section{Qualitative}

A purposeful convenience sample was selected for conducting two focus group sessions. Participants for the focus groups were recruited with the help of the Nebraska School Nutrition Association and the Nebraska Department of Education. Two focus group sessions were conducted at the Nebraska School Nutrition Association Annual Conference. Twenty participants were recruited who met criteria of being employed in the school foodservice setting and actively participating in NSLP. The sample of SFP included food-service managers, directors and head cooks ( $n$ 15) from fifteen different school districts that represented 7980 students enrolled in Nebraska schools.

Of the total fifteen participants, ten were school foodservice managers, three head cooks and two were directors. Focus group sessions lasted $50 \mathrm{~min}$. Each participant received a \$US 25 gift card for participating in the focus group. 


\section{Data collection tools}

Quantitative tool

Twenty-three questions were adopted from the $\mathrm{CATCH}^{(26)}$ study and School Foodservice Management Institutes ${ }^{(27)}$. The questions were based on the health belief model to assess participants' knowledge, attitudes, practices and their level of self-efficacy towards serving healthy meals in their schools. All questions were modified to meet the purpose of the present study. The survey questions assessed the attitudes, strategies and barriers in promoting healthy foods from USDA programmes and level of nutrition training received. One question was removed from the results, as the question was designed based on the MyPyramid icon which had subsequently changed to the MyPlate icon without modification. The question asked, "According to "Choose MyPlate", which food group should provide the bulk of your diet?' The question misled participants since the main message of MyPlate is that half of your plate should be fruits and vegetables and there was no combined statement referencing 'fruits and vegetables' provided as an option. According to MyPyramid, grains provide the bulk of an individual's diet.

Participants' demographic information was also collected. Cronbach's $\alpha$ was measured to determine the level of reliability for questions related to strategies (0.468) and attitude $(0 \cdot 729)$.

Two methods were utilized for the purpose of validation of the survey:

1. Face validity. Questions were reviewed by three experts in the field of school food service at the Nebraska Department of Education/Nutrition Services and one expert in the field of data, research, evaluation and information technology at the Nebraska Department of Education.

2. Content validity. Cognitive interviews were conducted with a sample of six school food-service managers/ directors. Modifications were made to the survey based on feedback. The survey was additionally pre-tested by three SFP to validate the survey questions and estimate the time for completing the survey.

Reliability of the instrument was accomplished through pilot testing prior to administration. The pilot group consisted of a convenience sample of six sites of school foodservice directors in Nebraska that were not included in the study. The participants of the pilot test were from rural and urban locations that represented a total of 4099 students. Cronbach's $\alpha$ was measured to determine the level of reliability for questions related to practices (0.468), knowledge (0.518), attitude (0.729) and self-efficacy (0.675).

\section{Qualitative tool}

Thirteen questions were developed to describe the nutrition knowledge of SFP and the school food environment, contextualize attitudes and strategies of SFP towards offering and serving healthy school meals, and barriers SFP face in offering and serving healthy school meals.

Three strategies were utilized for validation of the qualitative findings of the study:

1. Peer review or debriefing ${ }^{(28)}$ sessions, which were provided by two professors specialized in child nutrition.

2. Member checking ${ }^{(28)}$, which refers to verifying the final themes identified by the research with participants. The final report of the descriptive themes was sent to two participants of the focus groups to determine the accuracy of the researcher interpretation.

3. Researcher reflexivity ${ }^{(28)}$, which refers to the continuous process of reflection and examination of both the researcher and the relationship to the research to minimize bias. The researcher has work experience with child nutrition/NSLP and understood how SFP interacted and worked together through much of the process. The researcher acknowledged this background experience before and throughout the study to minimize any bias during data collection and analysis.

\section{Data analysis procedures}

Quantitative analysis

Data collected from the surveys were converted into a Microsoft Excel v.14 spreadsheet and transferred into the statistical software package IBM SPSS Statistics version 20.0. The quantitative data were correlational and descriptive in nature. Descriptive statistics including frequencies, means and standard deviations were computed. Internal consistency was measured to determine the intercorrelations between the items measuring practices, knowledge and self-efficacy. Additionally, a $t$ test was used to calculate differences between means. Frequencies and percentages were utilized to assess the variables. Cronbach's $\alpha$ was measured for the survey to determine the level of reliability for questions related to practices $(0 \cdot 468)$, knowledge (0.518), attitude (0.729) and self-efficacy (0.675). The values of $\alpha$ were likely below the accepted cut-off of 0.7 because some of the scales had fewer items. Bivariate Pearson's correlations were used to interpret the associations between the variables of interest. The betweengroup differences (groups defined by occupation) in nutrition knowledge, attitude, offering healthy school meals and self-efficacy were examined using one-way ANOVA followed by Tukey's test for the post hoc analyses. Multiple linear regression models were used to test whether knowledge, attitude and self-efficacy of the food-service staff explained offering/serving healthy school meals while controlling for occupation of the respondents. 
Table 1 Level of agreement with each survey statement among the sample of school food-service professionals ( $n$ 260) involved in service delivery at schools participating in the US Department of Agriculture's National School Lunch Program, Nebraska, USA, June 2012

\begin{tabular}{|c|c|c|c|c|c|c|c|c|}
\hline \multirow[b]{2}{*}{ Survey question } & \multicolumn{2}{|c|}{ Strongly disagree } & \multicolumn{2}{|c|}{ Disagree } & \multicolumn{2}{|c|}{ Agree } & \multicolumn{2}{|c|}{ Strongly agree } \\
\hline & $n$ & $\%$ & $n$ & $\%$ & $n$ & $\%$ & $n$ & $\%$ \\
\hline $\begin{array}{l}\text { 1. Children who eat low-fat foods at school will be healthier } \\
\text { than children who do not eat low-fat foods at school }\end{array}$ & 1 & 0.4 & 43 & $16 \cdot 5$ & 173 & $66 \cdot 5$ & 40 & $15 \cdot 0$ \\
\hline $\begin{array}{l}\text { 2. Children who eat low-sodium foods at school will be } \\
\text { healthier than children who do not eat low-sodium foods at } \\
\text { school }\end{array}$ & 2 & $0 \cdot 8$ & 54 & $20 \cdot 8$ & 161 & $62 \cdot 0$ & 40 & $15 \cdot 0$ \\
\hline $\begin{array}{l}\text { 3. Children who eat fruits and vegetables at school will be } \\
\text { healthier than children who do not eat fruits and vegetables } \\
\text { at school }\end{array}$ & 2 & 0.8 & 27 & $10 \cdot 4$ & 160 & $61 \cdot 5$ & 67 & $25 \cdot 8$ \\
\hline $\begin{array}{l}\text { 4. Children who eat wholegrain foods at school will be } \\
\text { healthier than children who do not eat wholegrain foods at } \\
\text { school }\end{array}$ & 1 & 0.4 & 50 & $19 \cdot 0$ & 160 & $61 \cdot 5$ & 46 & $17 \cdot 7$ \\
\hline $\begin{array}{l}\text { 5. Children who are overweight have more health risks than } \\
\text { children who are normal weight }\end{array}$ & 2 & 0.8 & 17 & $6 \cdot 5$ & 120 & $46 \cdot 0$ & 117 & $45 \cdot 0$ \\
\hline $\begin{array}{l}\text { 6. What a child eats at home is more important to a child's diet } \\
\text { than what I serve at school }\end{array}$ & 73 & $28 \cdot 0$ & 179 & $68 \cdot 8$ & 1 & 0.4 & 1 & 0.4 \\
\hline
\end{tabular}

Scores reported on a 4-point Likert scale, with $1=$ 'strongly disagree' and $4=$ 'strongly agree'. The response options differed depending on question.

\section{Qualitative analysis}

Data collected from the focus group sessions were audiorecorded and transcribed by hand verbatim. Transcripts were analysed using the qualitative software package MaxQDA version 11. Individual transcripts were read first to familiarize the researcher with the data. Deductive coding was used based on the overall groupings of attitudes, practices, knowledge, barriers and self-efficacy; however, not all a priori groupings emerged as final themes due to lack of supporting codes. Transcripts were coded by segmenting and labelling the text with codes demonstrating similar concepts. These codes were then reduced through clustering groups of codes that represented larger overarching categories until all codes fit appropriately into the overall themes of attitudes, practices, knowledge and self-efficacy. Quotes were also collected and utilized.

\section{Mixed methods}

Final quantitative and qualitative results were merged by comparing the separately analysed quantitative and qualitative data to identify content areas that were represented in both data sets, and then comparing and contrasting the evidence within those content areas that were similar and dissimilar. This process resulted in groups, or themes, that fully described the essence of that given content area with supporting evidence ${ }^{(29,30)}$.

\section{Results}

\section{Participants}

Four hundred and eleven participants attended trainings and 260 participants responded to the paper survey across the state of Nebraska. The response rate was $63 \%$. Participants consisted of cashiers ( $n$ 4), cooks ( $n$ 34), cafeteria staff $(n 7)$, food-service directors ( $n$ 60), kitchen staff
( $n$ 27), managers ( $n$ 97), and others ( $n$ 26) which included superintendents, principals, dietitians, school secretaries and bookkeepers (missing responses, $n$ 5). SFP ( $n$ 15) were recruited from fifteen different school districts that represented 7980 students enrolled in Nebraska schools. Two focus group sessions were conducted at the Nebraska School Nutrition Association Annual Conference in Kearney. Participants were school food-service managers ( $n$ 10), directors ( $n$ 2) and head cooks ( $n$ 3). Participants' foodservice experience levels ranged from less than 3 years to more than 35 years.

\section{Themes}

Four themes emerged as a result of mixed-methods findings, including: (i) 'Mixed attitudes towards healthy meals'; (ii) 'Positive practices to promote healthy meals'; (iii) 'Mixed nutrition-related knowledge'; and (iv) 'Complex barriers'.

\section{Theme 1: Mixed attitudes towards bealtby meals}

SFP experienced both positive and negative attitudes towards healthy meals, which both quantitative and qualitative data were crucial in determining, as each source revealed opposite findings. Quantitative results demonstrated more positive attitudes, for instance $\geq 78 \%$ indicated positive attitudes towards children's weight status and the intake of healthy foods, including low-fat and lowsodium foods, fruits and vegetables, and whole grains (Table 1 illustrates the participants' level of agreement with each statement). Additionally, there was a positive correlation between attitude and the practice of offering/ serving healthy food items $(P<0.05)$.

Despite these positive findings, qualitative results demonstrated more nuances. Participants showed more negative feelings towards healthy foods in schools, often associated with lack of participation from other important adults in a child's life, including teachers, administration and 
Table 2 Frequency of participants' practices and self-efficacy towards serving/offering healthy school meals among the sample of school food-service professionals $(n 260)$ involved in service delivery at schools participating in the US Department of Agriculture's National School Lunch Program, Nebraska, USA, June 2012

\begin{tabular}{|c|c|c|c|c|c|c|}
\hline \multirow[b]{3}{*}{ Does your school... } & \multicolumn{6}{|c|}{ Practices } \\
\hline & \multicolumn{2}{|c|}{ Never } & \multicolumn{2}{|c|}{ Sometimes } & \multicolumn{2}{|c|}{ Always } \\
\hline & $n$ & $\%$ & $n$ & $\%$ & $n$ & $\%$ \\
\hline 1. Follow recipes, measuring all ingredients with standardized measuring utensils? & 1 & 0.4 & 73 & 28.0 & 179 & 68.0 \\
\hline 2. Serve menu items with standardized serving utensils? & 1 & 0.4 & 27 & $10 \cdot 0$ & 226 & $87 \cdot 0$ \\
\hline 3. Use fresh and/or frozen fruits and vegetables? & 0 & 0.0 & 84 & $32 \cdot 0$ & 172 & $66 \cdot 0$ \\
\hline \multirow[t]{3}{*}{ 4. Use wholegrain food items? } & 3 & 1.2 & 166 & $63 \cdot 8$ & 86 & $33 \cdot 0$ \\
\hline & \multicolumn{6}{|c|}{ Self-efficacy } \\
\hline & \multicolumn{2}{|c|}{ Not sure } & \multicolumn{2}{|c|}{ A little sure } & \multicolumn{2}{|c|}{ Very sure } \\
\hline How sure are you that you can... & $n$ & $\%$ & $n$ & $\%$ & $n$ & $\%$ \\
\hline 1. Offer/serve wholegrain items to your students? & 3 & $1 \cdot 2$ & 166 & $63 \cdot 8$ & 86 & 33.0 \\
\hline 2. Offer/serve fresh fruits and vegetables to your students? & 11 & 4.2 & 80 & $30 \cdot 8$ & 163 & $62 \cdot 0$ \\
\hline 3. Offer/serve low-sodium foods to your students? & 1 & 0.4 & 26 & $10 \cdot 0$ & 228 & $87 \cdot 7$ \\
\hline 4. Offer/serve low-fat foods to your students? & 14 & 5.4 & 124 & $47 \cdot 7$ & 115 & $44 \cdot 0$ \\
\hline
\end{tabular}

parents. Participants indicated that children do not want to select healthy foods and that 'obesity does not start in school' despite their high attitude scores quantitatively. Participants expressed that teachers have a responsibility towards educating students about proper nutrition to influence students' food choices and wanted to see teachers promoting school lunch, sitting and interacting with the children during lunchtime, and setting a good example. One participant suggested that the health teachers need to be involved, 'and I don't think it can only be us. I think the health teachers have to be really engaged.' Participants expressed that schools also need the support of parents so that children are receiving consistent messages. A participant said, 'I think a family's income is huge on it. The lower-income families can't afford to do organized sports and extracurricular activities and it's cheaper for them to eat at McDonalds than at home.' Some of the participants shared that some parents take advantage of the fact that their children eat two out of three meals at school and become dependent on the school to meet their child's nutrition needs; this leads the parents to put dinnertime as a low priority.

\section{Theme 2: Positive practices to promote bealthy meals}

A majority of SFP participated in positive practices to promote healthy meals, including offering, serving and encouraging/promoting practices. Quantitative results demonstrated that most participants always performed healthy preparation practices ( $\geq 66 \%$ always), aside from using whole grains (64\% sometimes). Table 2 shows participants' detailed level of agreement with preparation practices related to healthy choices including following recipes, measuring with the right utensils, and using fruits and vegetables and wholegrain items in their menus.

Self-efficacy may have contributed as a behavioural predictor to the positive practices demonstrated. Self-efficacy was the only construct significantly positively correlated with offering healthy meals $(r=0.237, \quad P=0 \cdot 00016)$; knowledge $(r=0.062, P=0.163)$ and attitude $(r=-0.103$, $P=0.05)$ were not significantly correlated with behaviour (Table 3). Self-efficacy was identified as a predictor of behaviour $(P<0 \cdot 001$; Table 4$)$. Participants indicated high levels of self-efficacy generally (Table 2 ).

Although self-efficacy did not emerge during focus groups, participants expanded upon their positive practices. Most participants shared what they were doing to promote the new meal pattern. For example, some mentioned they were purchasing more fruits and vegetables and others shared that they added more wholegrain items to the school menus. A participant remarked, 'Our [menu] is more focused on the healthy because I didn't know really you could even offer cookies or sweet[s].' Additionally, participants shared ways to communicate and promote USDA-aligned school meals to parents and students. A participant shared the following comment: 'I really want to introduce a newsletter. I personally feel like as a professional, I can do what we started to talk about. Things are going to change.' Another participant added, 'I started to change the portion size of cookies to a smaller size and I told teachers and students that my supplier sent the wrong thing so they wouldn't complain.' One participant gave an example of how she verbally communicated healthier eating to her students by stating, 'I promote the vegetables through the line by saying, "Guys this is really good, it's fresh and steamed", and tell them not to forget their vegetables because they're healthy.' 


\section{Theme 3: Mixed nutrition-related knowledge}

SFP indicated a desire to learn to compensate for deficiencies. The majority of participants were able to select correct answers for questions related to dark green vegetables; the benefits of consuming fruits and vegetables, and dietary fibre; MyPlate; and the American diet. However, participants struggled with selecting the correct answer for dry beans, peas and whole grains. Table 5 shows the distribution of the correct knowledge of respondents; post hoc analyses for the ANOVA did not show any significant differences in knowledge scores among occupation groups.

Participants further described knowledge in terms of both themselves as well as other adults and students. Suggestions were made by participants to have trainings or workshops available to teachers, parents and students when there are major changes that impact child nutrition to aid in increasing knowledge. Participants described the need of educating teachers, parents and students as part of school-wide efforts that could additionally help support the selection of healthy meals: 'If the kids were educated about what a body needs for calorie intake a day and if they really wanted to be fit, they would bypass that junk food ... if they knew MyPlate.' Other participants expressed their interest of having registered dietitians, nurses or staff from Extension provide some educational lessons related to food and nutrition to support their ability to offer healthy meals. Participants shared their preferred

Table 3 Pearson's correlations between nutrition knowledge, attitude, self-efficacy and offering healthy school meals among the sample of school food-service professionals $(n 260)$ involved in service delivery at schools participating in the US Department of Agriculture's National School Lunch Program, Nebraska, USA, June 2012

\begin{tabular}{lc}
\hline Relationship between... & $\begin{array}{c}\text { Correlation, significance } \\
\text { (one-tailed) }\end{array}$ \\
\hline $\begin{array}{l}\text { Offering healthy meals and knowledge } \\
\text { Self-efficacy and knowledge }\end{array}$ & $r=0.062, P=0.163$ \\
Attitude and knowledge & $r=0.034, P=0.294$ \\
Self-efficacy and offering healthy meals & $r=0.047, P=0.05^{\star}$ \\
Offering healthy meals and knowledge & $r=0.062, P=0.163$ \\
Attitude and offering healthy meals & $r=0=0.103, P=0.05$ \\
Knowledge and attitude & $r=0.105, P=0.047^{\star}$ \\
Self-efficacy and attitude & $r=0.069, P=0.135$ \\
\hline
\end{tabular}

*Significant at the $a=0.05$ level (one-tailed). type of delivery method, which was face-to-face or classroom workshops rather than online webinars. This method would give them the chance to share and hear ideas from others in the same field, as well as more time to ask questions. In addition, they preferred this mode of learning because most of them were not familiar with using computers. Participants reinforced the idea that trainings should also be available to other staff from their school districts. Some of the participants shared current obstacles that prevent their staff from attending trainings related to food and nutrition, such as a lack of emphasis on training and continuing education. A participant remarked, 'My school district, before I became the director there, did not require people to go to attend trainings.'

\section{Theme 4: Complex barriers}

Finally, SFP described a variety of barriers that made serving healthy meals more difficult. Quantitative results demonstrated that time was a barrier. Most SFP spent 2-4 h on food preparation, cooking food, serving food and cleaning up/dishwashing; however, quantitative results did not reveal much detail.

Focus groups dug deeper into the barriers SFP faced. Time was a difficulty both for staff and children. Participants mentioned that lunchtime is very short, especially for young students, because there is no time for them to sit, chew, eat and enjoy their lunch. Additionally, they mentioned that recess is scheduled after lunch so consequently students hurry to eat their lunch to get more recess time. One participant remarked, 'I think the younger kids take more time. In my school I think they need at least five to ten minutes more than what they are getting now.' Lack of time to attend or participate in continuing education opportunities was expressed as a challenge. One participant commented, 'Some people maybe don't want to take it [training] out of their summer vacation.' Additionally, paperwork consumed most of their time and responsibilities, which prevented them from preparing foods from scratch, forcing them to use more ready-to-eat, convenience foods.

Participants also expressed the barrier that they did not have the full support of school administration and teachers in order to promote the new meal pattern and healthy eating habits. One participant remarked, 'I'd like to go

Table 4 Relationships between nutrition knowledge, attitude, self-efficacy and offering healthy school meals among the sample of school food-service professionals ( $n$ 260) involved in service delivery at schools participating in the US Department of Agriculture's National School Lunch Program, Nebraska, USA, June 2012

\begin{tabular}{llccrrr}
\hline Dependent variable & Predictor & $\begin{array}{c}\text { Unstandardized } \\
\text { beta }\left(\beta_{1}\right)\end{array}$ & $\begin{array}{c}\text { Standardized } \\
\text { beta }(\beta)\end{array}$ & $t$ & \multicolumn{1}{c}{$R^{2}$} & $\begin{array}{c}\text { Adjusted } \\
R^{2}\end{array}$ \\
\hline $\begin{array}{l}\text { Offering healthy } \\
\text { mealst }\end{array}$ & Knowledge & 0.061 & 0.077 & 1.212 & 0.117 & 0.083 \\
& Self-efficacy & 0.166 & 0.237 & 3.835 & 0.227 \\
& Attitude & -0.047 & -0.109 & -1.752 & $<0.001$ \\
& & & 0.081 \\
\hline
\end{tabular}

Linear regression analysis. Demographic characteristics (occupation) were used as control variables.

†Offering/serving healthy meals. 
Table 5 Percentage of participants with correct knowledge among the sample of school food-service professionals ( $n 260)$ involved in service delivery at schools participating in the US Department of Agriculture's (USDA) National School Lunch Program, Nebraska, USA, June 2012

\begin{tabular}{lc}
\hline Question & $\begin{array}{c}\text { \% of correct } \\
\text { response }\end{array}$ \\
\hline $\begin{array}{l}\text { 1. According to the USDA new meal pattern, all } \\
\text { the following items are classified as dark }\end{array}$ & 63 \\
$\begin{array}{l}\text { green vegetables except ...? } \\
\text { 2. All the following items are whole grain except }\end{array}$ & 41 \\
$\begin{array}{l}\text { 3. All the following items are classified as dry } \\
\text { beans or peas except ...? }\end{array}$ & 45 \\
$\begin{array}{l}\text { 4. Eating fruits and vegetables and using whole- } \\
\text { wheat pasta helps boost the __ content of } \\
\text { foods? }\end{array}$ & 85 \\
$\begin{array}{l}\text { 5. Dietary fibre decreases the risk of which of the } \\
\text { following health problem? }\end{array}$ & 73 \\
6. Which of the following do Americans need to \\
consume more of?
\end{tabular}

beyond the parents because I want the teachers to know also so they can prepare the students when they come out [new meal pattern]. In the classroom, teachers can ask the students about their lunch and if they hear something negative, they can back us up because we support them. They need to support us.' In regard to teaching healthy eating habits, a participant suggested that the health teachers need to be involved. Participants conveyed they did not feel comfortable relaying information to administration and teachers because of their education level and job title. Participants expressed that administrators preferred to hear from higher-level sources. One participant stated, 'They don't communicate with us because they think it's just us. If they heard it from a higher authority then they would know, believe us, and maybe trust and listen to us more.'

\section{Discussion}

Few studies examine SFP perspectives on school meals, particularly since the implementation of the HHFKA ${ }^{(23)}$. The findings of the present study attempt to shed light on perspectives to inform efforts that might be successful for providing support for SFP in the school meal programme. The two main areas identified that SFP could use support on were: (i) reducing barriers related to negative attitudes and lack of support, both of which could be tackled with a more holistic all-school approach and strategic communication plan; and (ii) increasing knowledge through supportive training.

Mixed-methods results demonstrated two areas in which schools could intervene to better support SFP, the first of which was reducing barriers related to attitudes and lack of support. Results demonstrated mixed attitudes towards offering/serving healthy school meals, as well as concerns regarding teachers', students' and parents' attitudes towards offering/serving healthy school meals. Participants reported foundational positive attitudes towards the concept of healthy foods combatting childhood obesity, but negative attitudes towards students selecting foods, general lack of staff support, and a lack of knowledge from parents and teachers that could have a negative influence on children's eating habits. Role models, such as parents and teachers, do have a significant impact on behaviours, including healthy eating and physical activity ${ }^{(24,31)}$. However, teacher and parent behaviours perceived by SFP in the present study are expected to have a negative effect on the eating habits of students $^{(31)}$. SFP spend less time with children than either teachers or parents and are less likely to have an impact as a role model despite foundational positive attitudes about healthy meals and good intentions to improve health.

Lack of support was not only related to negative attitudes, but was identified directly as a barrier for SFP in trying to offer/serve healthy school meals, which has been identified previously in quantitative studies ${ }^{(32,33)}$. Recent qualitative research, however, has not identified lack of support as a barrier ${ }^{(34)}$. Although Slawson et al. provide some qualitative insight into lack of support, exploration with staff was within the context of a specific intervention, limiting the broader implications of the findings ${ }^{(35)}$. Therefore, the present study demonstrates novel and indepth findings regarding lack of support SFP feel, suggesting an urgent need for a full-school approach to promote and encourage healthy eating habits among students, as well as facilitation with communication strategies.

SFP indicated a variety of reasons for lack of support, all contributing to minimal communication throughout the school: lower perceived status, lower education, lack of comfort with communication and lack of trust. Communication with parents was also a barrier, which has previously been indicated by teachers ${ }^{(36)}$ and in childcare settings ${ }^{(37,38)}$, further emphasizing the need for a fullschool approach and communication assistance to promote consistent nutrition messaging in a child's life.

To solve these barriers, these contributing findings described would indicate that schools that better integrate teachers and parents into the school meal programme may have more success at reducing SFP negative attitudes and perception of lack of support while creating role models that consistently reinforce similar healthy messages. Although literature regarding the most effective school interventions is mixed, reviews have noted that this may be related to lack of outcomes selected to evaluate a programme, not actual lack of success, and it is still recommended to implement multicomponent interventions, such as those that engage multiple adult role mod$\mathrm{els}^{(39,40)}$. Additionally, to support staff, a communication plan could be established by the school to communicate within and outside of the school, with the help of partners 
such as local community or university stakeholders. School wellness committees that encourage members from teaching, food-service and administration staff, parents and students can help to create a communication channel with wide representation to assure different staff groups and parents are communicating and creating a diverse group to set school wellness policies. Clear expectations for communication back to respective subgroups after each meeting would help to keep all staff in the loop, and strategies such as anonymous comment boxes, surveys or quarterly check-ins with subgroups could help to assure that everyone's voice is heard. Basic educational nutrition communications sent home with accompanying menus can help support parents in providing children consistent healthy messaging. Additionally, educational programming tailored to the school that underscores USDA's main Choose MyPlate messaging to promote behaviour change may help SFP feel more positive about other school staff supporting their roles in the cafeteria ${ }^{(41)}$.

The results of the present study also demonstrated mixed knowledge depending on the topic area. Although participants were knowledgeable about the benefits of eating fruits, vegetables and fibre, the majority of the participants struggled to identify wholegrain items and dry beans items, which is important to address to support SFP in their roles. Lack of knowledge about identifying wholegrain items and dry beans/legumes indicates the need for educating SFP on some basic food components. SFP need to understand not only the general guidelines, but also how to apply them to school meals ${ }^{(42-44)}$. A study by Roth-Yousey et al. reported that providing continuing education for SFP on whole grains was found to improve menu placement and awareness, suggesting that nutrition knowledge influences food-service menus and that training SFP could be beneficial ${ }^{(45)}$.

Since results suggest that a positive correlation exits between SFP's self-efficacy and their practices of offering/ serving healthy school meals, active trainings that also pursue an increase in self-efficacy would be ideal to increase the potential for both knowledge and behaviour change. The concept of self-efficacy, introduced by Bandura, refers to a person's confidence in his/her capacity to successfully perform a given task or behaviour to manage prospective situations ${ }^{(46)}$. Higher level of self-efficacy affects employees' goal setting and can positively affect performance $^{(47-49)}$. With SFP as the direct line to healthy meals, it is critical that the proper training opportunities are offered related to food and nutrition to provide healthy school meals. Training should avoid lecture-based, traditional classroom-style only learning, as this does not promote self-efficacy. Instead, training should incorporate interactive activities that incorporate hands-on learning, mastery experience, verbal/social persuasion and group learning ${ }^{(50,51)}$. Although the present findings support previous findings that SFP have limited knowledge on whole grains, schools should be assessed for their staff's knowledge needs and provided hands-on training to help meet those needs ${ }^{(52)}$.

Additionally, participants indicated a high level of interest in receiving trainings that would improve the quality of their employees' performance, develop general leadership skills and explore factors that motivate their employees. The findings of the present study concur with the findings of Sullivan et al. which indicated that school food-service directors report interest in developing and implementing trainings and workshops that address the quality of their school's food-service programme ${ }^{(53)}$, employee performance, and general leadership skills for their staff ${ }^{(19,32,35,42,52-55)}$. To keep up the positive behaviours demonstrated in the present study, such as positive serving practices and the verbal encouragement for students, keeping SFP motivated through meeting their personal goals is key.

\section{Limitations}

The present study will fill a gap in the literature regarding SFP attitudes, knowledge, barriers and practices of offering/serving healthy school meals. However, some limitations exist. The survey was conducted during summer trainings and although $90 \%$ of participants were SFP, $10 \%$ of participants were bookkeepers, cashiers, principals and other school staff who do not directly plan or serve school meals and do not fully represent SFP practices. However, in small rural districts, such individuals play a key role in providing day-to-day management and oversight of the programme through district-level food purchasing, procurement, menu development, documentation and statelevel claims processing for reimbursement, making them instrumental to overall food-service programme management similar to food-service directors in an urban setting. Their knowledge of the types of foods served and the nutritional content of meal programme offerings would be as accurate as those of the food-service staff completing the surveys and so were included in the analysis to avoid disproportionately removing rural districts from the analysis. Convenience sampling was used and respondents may be inherently different from non-respondents, which may limit the generalizability of the study.

\section{Implications for future research}

A follow-up study could be conducted using the current study design as a starting point to develop educational or communication interventions that target SFP, teachers, students and their parents. For instance, one example would be a trial using a specific communications intervention a school or district develops to decrease the perceived barrier of lack of support and to decrease negative attitudes towards teachers' and parents' perceived lack of knowledge. 
Additional investigation targeting rural and urban schools and the differences in those schools could also be researched to identify barriers and points of leverage specific to each area to create interventions that best address each unique type of school.

\section{Conclusions}

The present study produced relevant findings which will allow stakeholders to address the barriers identified. Schools and their stakeholders could benefit from these findings to:

1. better participate in a whole-school, multicomponent approach that engages staff at all levels and parents;

2. establish a communications plan with a representative wellness committee, with the help of local partners if necessary, for the dissemination of school nutrition programme information; and

3. train SFP to increase school food knowledge and professional development knowledge to maintain or increase professional motivation.

\section{Acknowledgements}

Acknowledgements: The authors would like to thank the school food-service personnel who participated in this study for their involvement and sharing their stories. The authors would also like to thank Dr Wanda Koszewski, Dr Tim Carr and Dr Candace Kohnke for their recommendations, advice and support throughout the process of this study. Financial support: This project was funded by the Cooperative State Research, Education, and Extension Service, the Agriculture and Food Research Initiative (AFRI; grant number 2011-6700230202) from the USDA National Institute of Food and Agriculture. This project was also supported by the Nebraska Department of Education/Nutrition Services. The funders had no role in the design, analysis or writing of this article. Conflict of interest: None. Authorship: Each author contributed in the following aspects of research. Z.R.: obtaining funding, supervision, administrative support, drafting the manuscript, critical revision, interpretation of the data. E.H.: critical revision, drafting of the manuscript. S.H.: critical revision, data analysis. J.C.: critical revision, drafting of the manuscript. D.A.D.: reviewing the manuscript. Ethics of buman subject participation: This study complied with ethical standards following the World Medical Association (2000) Declaration of Helsinki: Ethical Principles for Medical Research Involving Human Subjects. The project was approved by the University of Nebraska-Lincoln Institutional Review Board and informed consent was obtained from study participants.

\section{References}

1. US Department of Health and Human Services, Centers for Disease Control and Prevention (2013) Results from the school health policies and practices study 2012. https:// www.cdc.gov/healthyyouth/shpps/2012/pdf/shpps-results_ 2012.pdf (accessed October 2017).

2. Story M, Kaphingst KM \& French S (2006) The role of schools in obesity prevention. Future Child 16, 109-142.

3. Story M, Nanney MS \& Schwartz MB (2009) Schools and obesity prevention: creating school environments and policies to promote healthy eating and physical activity. Milbank Q 87, 71-100.

4. French SA, Story M, Fulkerson JA et al. (2004) An environmental intervention to promote lower-fat food choices in secondary schools: outcomes of the TACOS Study. Am J Public Health 94, 1507-1512.

5. Kubik MY, Lytle LA \& Story M (2005) School wide food practices are associated with body mass index in middle school students. Arch Pediatr Adolesc Med 159, 1111-1114.

6. Li J \& Hooker NH (2010) Childhood obesity and schools: evidence from the national survey of children's health. J Sch Health 80, 96-103.

7. Perry CL, Bishop DB, Taylor GL et al. (2004) A randomized school trial of environmental strategies to encourage fruit and vegetable consumption among children. Health Educ Behav 31, 65-76.

8. Asada Y, Ziemann M, Zatz L et al. (2017) Successes and challenges in school meal reform: qualitative insights from food service directors. $J$ Sch Health 87, 608-615.

9. 108th Congress (2004) Child Nutrition and Women, Infants, and Children Reauthorization Act of 2004, Public Law No. 108-265. https://www.govinfo.gov/content/pkg/PLAW-108 publ265/pdf/PLAW-108publ265.pdf (accessed October 2017).

10. 111th Congress (2010) Healthy, Hunger-Free Kids Act of 2010, Public Law No. 111-296, 124 Stat. 3183, Sec. 201, 203. https://www.govinfo.gov/content/pkg/PLAW-111publ296/ pdf/PLAW-111publ296.pdf (accessed March 2019).

11. US Department of Agriculture, Food and Nutrition Service (2016) Local School Wellness Policy Implementation under the Healthy, Hunger-Free Kids Act of 2010, final rule. Fed Regist 81, 50151. https://www.gpo.gov/fdsys/pkg/FR-201607-29/pdf/2016-17230.pdf (accessed November 2017).

12. US Department of Agriculture, Food and Nutrition Service (2012) National School Lunch Program. http://www.fns. usda.gov/cnd/lunch/(accessed November 2017).

13. Hoffman V, Srinivasan M, Levin M et al. (2018) Operating school meal programs in rural districts: challenges and solutions. J Child Nutr Manag 42, issue 1; available at https://schoolnutrition.org/uploadedFiles/5_News_and_Pub lications/4_The_Journal_of_Child_Nutrition_and_Management/ Spring_2018/Operating-School-Meals-in-Rural-Districts-Challen ges-and-Solutions-Spring2018.pdf

14. Food Research \& Action Center (2015) National School Lunch Program. http://frac.org/federal-foodnutrition-programs/ national-school-lunch-program/ (accessed November 2017).

15. Pew Charitable Trusts \& Robert Wood Johnson Foundation (2013) Serving healthy school meals: US schools need updated kitchen equipment. https://www.pewtrusts.org/ /media/assets/2015/08/serving_healthy_school_meals_ report.pdf (accessed September 2017). 
16. Newman C (2013) Fruit and Vegetable Consumption by School Lunch Participants: Implications for the Success of New Nutrition Standards. Economic Research Report no. ERR-154. Washington, DC: US Department of Agriculture, Economic Research Service; available at https://agecon search.umn.edu/record/262220/files/39888_err154.pdf

17. Kubik MY, Lytle LA, Hannan PJ et al. (2003) The association of the school food environment with dietary behaviors of young adolescents. Am J Public Health 93 , 1168-1173.

18. Fox MK, Dodd AH, Wilson A et al. (2009) Association between school food environment and practices and body mass index of US public school children. J Am Diet Assoc 109, 2 Suppl., S108-S117.

19. Wechsler H, Devereaux RS, Davis M et al. (2000) Using the school environment to promote physical activity and healthy eating. Prev Med 31, Suppl., S121-S137.

20. Cullen KW \& Watson K (2007) Measuring school foodservice employees' perceptions of organizational culture. J Child Nutr Manag 31, issue 1; available at https://schoolnutrition. org/uploadedFiles/5_News_and_Publications/4_The_Journal_ of_Child_Nutrition_and_Management/Spring_2007/6-cullen. pdf

21. Lamkin ML (2006) Challenges and changes faced by rural superintendents. Rural Educator 28, 17-24.

22. Cornish DL, Askelson NM \& Golembiewski EH (2015) Professional networks among rural school food service directors implanting the Healthy, Hunger-Free Kids Act. $J$ Child Nutr Manag 39, issue 1; available at https://school nutrition.org/uploadedFiles/5_News_and_Publications/4_ The_Journal_of_Child_Nutrition_and_Management/Spring 2015/868\%20Revised\%20Manuscript\%20Print\%20Ready\% 203-12-15\%20Final.pdf

23. Yuka A, Ziemann M, Zatz L et al. (2017) Successes and challenges in school meal reform: qualitative insights from foodservice directors. J Sch Health 87, 608-615.

24. Bandura A (1986) Social Foundations of Thought and Action: A Social Cognitive Theory. Englewood Cliffs, NJ: Prentice-Hall.

25. Creswell J \& Plano Clark V (2011) Designing and Conducting Mixed Methods Research, 2nd ed., pp. 116-119. London: SAGE Publications Ltd.

26. Hoelscher DM, Feldman HA, Johnson CC et al. (2004) School-based health education programs can be maintained over time: results from the CATCH institutionalization study. Prev Med 38, 594-606.

27. Gordon A \& Fox MK (2007) School Nutrition Dietary Assessment Study-III. Washington, DC: US Department of Agriculture, Food and Nutrition Service; available at https:// www.fns.usda.gov/school-nutrition-dietary-assessmentstudy-iii

28. Creswell JW \& Miller DL (2000) Determining validity in qualitative inquiry. Theory Pract 39, 124-130.

29. Creswell JW \& Plano Clark VL (2011) Designing and Conducting Mixed Methods Research, 2nd ed., pp. 203-250. Thousand Oaks, CA: SAGE Publications, Inc.

30. Teddlie C \& Tashakkori A (2009) Foundations of Mixed Methods Research: Integrating Quantitative and Qualitative Approaches in the Social and Behavioral Sciences, 1st ed., pp. 249-284. Thousand Oaks, CA: SAGE Publications, Inc.

31. Ritchie LD, Welk G, Styne D et al. (2005) Family environment and pediatric overweight: what is a parent to do? $\mathrm{J} \mathrm{Am}$ Diet Assoc 105, 5 Suppl., S70-S79.

32. Alcaraz B \& Weber Cullen K (2014) Cafeteria staff perceptions of the new USDA school meal standards. J Child Nutr Manag 38, issue 2; available at https://schoolnutrition.org/ uploadedfiles/5_news_and_publications/4_the_journal_of_ child_nutrition_and_management/fall_2014/cafeteriastaff perceptionsofthenewusdaschoolmealstandards.pdf
33. Brouse CH, Wolf RL \& Basch CE (2009) School foodservice director's perceptions of the barriers to and strategies for improving the school food environment in the United States. Int J Health Promot Educ 47, 88-93.

34. Yon BA, Amin SA, Taylor JC et al. (2016) School nutrition directors' perspectives on preparing for and implementing USDA's new school meal regulations. J Child Nutr Manag 40, issue 1; available at https://schoolnutrition.org/uploaded Files/5_News_and_Publications/4_The_Journal_of_Child_ Nutrition_and_Management/Spring_2016/4-SchoolNutrition DirectorsPerspectives.pdf

35. Slawson DL, Southerland J, Lowe EF et al. (2013) Go Slow Whoa meal patterns: cafeteria staff and teacher perceptions of effectiveness in winning with wellness schools. $J$ Sch Health 83, 485-492.

36. Hall E, Chai W \& Albrecht J (2015) A qualitative phenomenological exploration of teachers' experience with nutrition education. Am J Health Educ 47, 136-148.

37. Johnson SL, Ramsary S, Shultz A et al. (2013) Creating potential for common ground and communication between early childhood program staff and parents about young children's eating. J Nutr Educ Behav 45, 558-568.

38. Dev D, Byrd-Williams C, Ramsay S et al. (2016) Let's work together towards children's nutrition: building bridge between child care providers and parents for promoting child health. J Nutr Educ Behav 48, issue 7, S71.

39. Amini A, Djazayery A, Majdzadeh R et al. (2015) Effect of school-based interventions to control childhood obesity: a review of reviews. Int J Prev Med 6, 68.

40. Guerra PH \& Cardoso da Silveira JA (2016) Physical activity and nutrition education at the school environment aimed at preventing childhood obesity: evidence from systematic reviews. J Pediatr (Rio J) 92, 15-23.

41. Langford R, Bonell C, Jones H et al. (2015) Obesity prevention and the Health promoting Schools framework: essential components and barriers to success. Int J Behav Nutr Phys Act 12, 15.

42. Smith KN, Bergman EA, Englund T et al. (2016) School lunch quality following Healthy, Hunger-Free Kids Act implementation. J Child Nutr Manag 40, issue 1; available at https://schoolnutrition.org/uploadedFiles/5_News_and_ Publications/4_The_Journal_of_Child_Nutrition_and_Man agement/Spring_2016/3-SchoolLunchQuality.pdf

43. Gross SM \& Cinelli B (2004) Coordinated school health program and dietetics professionals: partners in promoting healthful eating. J Am Diet Assoc 104, 793-798.

44. Au LE, Rosen NJ, Fenton K et al. (2016) Eating school lunch is associated with higher diet quality among elementary school students. J Acad Nutr Diet 116, 1817-1824.

45. Roth-Yousey L, Barno T, Caskey M et al. (2009) Whole-grain continuing education for school foodservice personnel: keeping kids from falling short. J Nutr Educ Behav $\mathbf{4 1}$, 429-423.

46. Bandura A (2004) Health promotion by social cognitive means. Health Educ Res 31, 143-164.

47. Fulkerson JA, French SA, Story M et al. (2002) Foodservice staff perceptions of their influence on student food choices. J Am Diet Assoc 102, 97-99.

48. Meyer MK (2000) Top predictors of middle/junior high school students' satisfaction with school foodservice and nutrition programs. J Am Diet Assoc 100, 100-103.

49. Murphy AS, Sawyer CA, Hoerr SL et al. (1995) School foodservice personnel knowledge of, interest in, and application of the dietary guidelines. Sch Foodserv Res Rev 2, 61-65.

50. Glaz K, Rimer B \& Viswanath K (2008) Health Behavior and Health Education Theory Research and Practice. San Francisco, CA: Jossey-Bass Publishers.

51. DiClemente R, Salazar LF \& Crosby RA (2010) Health Behavior Theory for Public Health: Principles, Foundations, 
and Applications. Burlington, MA: Jones and Bartlett Learning.

52. Chan HW, Hesse D, Arndt E et al. (2009) Knowledge and practices of school foodservice personnel regarding whole grain foods. J Food Serv 20, 109-116.

53. Sullivan K, Harper M \& West CK (2001) Professional development needs of school foodservice directors. J Cbild Nutr Manag 25, 35-42.
54. Basch CE (2011) Healthier students are better learners: a missing link in school reforms to close the achievement gap. J Sch Health 81, 593-598.

55. Basch CE (2011) Healthier students are better learners: highquality, strategically planned, and effectively coordinated school health programs must be a fundamental mission of schools to help close the achievement gap. J Sch Health $\mathbf{8 1}$, 650-662. 